\title{
Forgiveness and Moral Reckoning
}

\author{
Howard Wettstein
}

Received: 16 January 2010 / Accepted: 19 January 2010 /

Published online: 19 May 2010

(C) The Author(s) 2010. This article is published with open access at Springerlink.com

\begin{abstract}
Charles Griswold's seminal work, Forgiveness, is the focus of the present essay. Following Griswold, I distinguish the relevant virtue of character from something that is more like an act or process. The paper discusses a number of hesitations I have about Griswold's analysis, at the level both of detail and of underlying conception.
\end{abstract}

Keywords Forgiveness $\cdot$ Moral anger $\cdot$ Paradigm $\cdot$ Resentment

Forgiveness is no simple matter either to execute or to understand. Charles Griswold explores forgiveness both in its guise as a virtue - I'll call it "forgivingness"- and as something that's more difficult to categorize, something like an act or process. Griswold's Forgiveness provides a classical philosophical analysis of the act or process, "a theory of paradigmatic forgiveness - of what forgiveness would have to be in order to be perfectly accomplished." Griswold's is a fine book, one that serves as at once an able introduction to and an accomplished advanced treatment of a set of difficult and important questions.

One of Wittgenstein's legacies, one emphasized by Kripke, is an approach to philosophic criticism that attends both to the details of views under discussion as well as, perhaps even more significantly, the underlying conception, what Kripke refers to as the picture of the domain. I will initially focus on a number of my hesitations concerning Griswold's analysis of forgiveness, the act or process, his concern in the central portions of his book. I will raise matters of detail that at the same time signal the need for a very different underlying conception. Afterward, I turn to the virtue, some of whose features make this need even more dramatic.

\section{Hesitation: Moral Anger and Resentment}

Griswold, along with much of the literature, sees forgiveness as to some large extent a matter of overcoming the offended party's "moral anger," "moral hatred" and like phenomena. The adjective "moral" draws attention to itself here. There is a tradition of

H. Wettstein $(\bowtie)$

University of California, Riverside, Riverside, CA, USA

e-mail: howard.wettstein@ucr.edu 
the use of the term, "moral," according to which morality is not implicated; modern philosophers speak of the moral sciences, where "moral" means something like "concerning human nature" or "concerning human mores." Griswold's use of "moral anger," "moral hatred," and the like seem, however, part of a conception of the domain which sees it as highly moralized, beginning with a unjustified moral intrusion. Forgiveness, on Griswold's view, pivots on the offended party's moral reckoning.

Are the offences for which apology and forgiveness are appropriate always, typically, or paradigmatically moral offences? Are all significant breaches in human relations moral breaches? Arguably even offensive personal affronts are not always moral wrongs. Examples are plentiful: breaches of courtesy, speech that is too harsh, various kinds of presumption, a pattern of behavior that while disturbing is too close to the line to be remarked on but that persists over time. Or consider the distribution of goods and attention within a family, where without ill will someone is hurt, perhaps lastingly. Self-absorbed, someone fails to attend adequately to another's pain or joy. It's difficult to see all such examples as involving moral wrongs. Clearly the question of delimiting the scope of morality is beyond my reach here. But Griswold's locating forgiveness in strictly moral terrain is, I think, very significant, and I'll return to it below. ${ }^{1}$

Griswold sees "moral anger" as a justified consequence of personal offence; he speaks similarly of "resentment." It is not altogether clear from the text whether these are precisely the same concepts. But clearly they are close, and perhaps the same. The idea seems to be that there is in the well functioning moral agent's response to offense something relatively uniform, in Bishop Butler's terms "a species of moral hatred..., a retributive passion that instinctively seeks to exact a due measure of punishment." (P. 39)

Why suppose any such uniformity? Our reactions to offence-moral, personal, or however one thinks of them-vary widely and along myriad dimensions: with personalities, contexts, social stratification, expectations, and the like. Anger is only one amongst many reactions. A sample of others are revulsion, sadness, depression with the state of things, annoyance, even relative indifference. And why presume that the desire for revenge is ubiquitous? Such an urge is no doubt a deep and primitive feature of human responsiveness to injury. But a deep feature is not necessarily a universal feature.

I mentioned indifference as one possible response. It is not a response that Griswold and others in this literature afford much respect. Griswold speaks as if such a reaction bespeaks most likely a lack of self-respect, or else, much less likely, a kind of sainthood. Sainthood aside, there are those no doubt who fail to react to offense (or who over-react) out of a lack of self-regard. However, many people at least some of the time refuse to take others' untoward behavior to heart and there is no simple story to be told about why. Indeed, sometimes it may be a function of psychological health and perspective. If one proceeds through the world with a well-developed sense of irony, perhaps grounded in a strong sense of self, all sorts of things become possible.

\footnotetext{
${ }^{1}$ There is a large question concerning the scope of the moral, perhaps independent of what I am raising here, but at least reminiscent of it. Bernard Williams and Harry Frankfurt, perhaps inspired by Nietzsche, distinguish the moral from the ethical, a much broader domain that includes our values, loves, and the like. Forgiveness may provide an interesting terrain to contrast such an approach like Griswold's that sees the category of the moral as overriding.
} 
And when there is anger, even at an uncontroversially moral offense, is one's reaction moral anger? What is moral anger? Is it a species of anger, one with a different phenomenology than other sorts, or rather one with different sorts of accompanying thoughts, or a merely different etiology? Assuming for a moment that there is some distinctively moral anger, it must be very difficult to tease it apart from a more personal anger. Such clarity would seem to be the last thing on the mind of typical victims. And need one add "moral" to the other reactions mentioned: moral depression, sadness, and the rest? What would be the point of such an addition? What work does "moral" do in talk of moral anger, hatred, and the like?

\section{Griswold's Analysis of Forgiveness: the Offender}

I turn to the heart of Griswold's analysis. Griswold formulates six conditions that must be satisfied by the offender, in paradigmatic cases of forgiveness. ${ }^{2}$

1. There are two parts to this first condition: the offender must first acknowledge that she was the responsible agent. And second, she must demonstrate that she no longer wishes "to stand by herself as the author of those wrongs."

2. She must repudiate her deeds and disavow that she would author those deeds again. This, Griswold explains, is a step toward showing that one is not simply the "same person" who did the wrong. One thus, in Griswold's words, "repudiates the self that did X."

3. The wrong-doer must both experience and express regret-not simply acknowledge the wrongness of the act-and the regret must be expressed to the wronged party.

4. The offender must commit to becoming the sort of person who does not inflict injury, and that commitment must be shown through deeds as well as words. ("Then," comments Griswold, "her repudiation of her 'past self' would become credible, and it is her task to make it so, for the 'burden of proof' is hers and hers alone to shift.")

These first four steps constitute a "contrition" condition. There are two additional conditions:

5. The offender must show that she understands, from the injured person's perspective, the damage done by the injury.

6. The offender needs to offer a narrative account of "how she came to do wrong, how that wrong-doing does not express the totality of her person, and how she is becoming worthy of approbation. She needs to make herself intelligible by offering up an account that is neither fiction nor excuse making, and that puts the wrong-doing as well as the self that did the wrong in context."

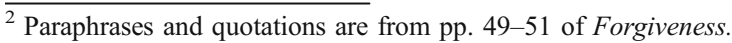




\section{Hesitation: What Did I Do???}

When I first studied these conditions I, one who regularly asks for forgiveness, felt as if I was losing touch with the project. Repudiation of the self? A full narrative that reveals that my offense does not represent the "totality" of my person? On the countless occasions I apologize, were I to issue any such full narrative or self repudiation, I would likely be looked at quizzically and be told to lighten up.

I will turn in a moment to Griswold's conception of these conditions as necessary only with respect to paradigm cases; this might be seen as blunting my concern about the conditions being overly extreme and dramatic. But I do want to register the sense that some of these conditions have purchase only with respect to severe, even heinous offenses. This threatens to skew any general account of forgiveness. Even if what is at issue are paradigm cases, it's not clear why the focus should be the most heinous offenses.

It took me some time to see what Griswold was after in his talk of paradigms, since I took the term to refer to classical or typical cases. One learns the meaning of terms, one might suppose in the spirit of Wittgenstein or psychologist Eleanor Rosch, by acquaintance with paradigms, typical cases, rather than by the intellectual mastery of definitions. And if one uses paradigm in this Wittgensteinian way, Griswold's talk of paradigms and the analysis he proposes for them is indeed very difficult to assimilate.

Attention to the beginning of Chapter 3, however, revealed that I had missed Griswold's intention. Griswold's "paradigm" talk derives not from Wittgenstein but from Plato: paradigm as perfect exemplar. Griswold's view is that the sort of extreme cases of moral breach that he emphasizes and the forgiveness that is appropriate to them constitute a sort of perfect example of the phenomena in which he is interested.

Still, the connection between extreme cases and perfect ones remains obscure to me. In what way are the extreme cases perfect examples? And why assume that the human resolution of heinous moral offenses somehow models for us the resolution of everyday hurts and indignities? In what way are the ordinary examples reflections of the extreme ones. My own contrary, Wittgensteinian instinct is to make a study of our actual practices of forgiveness focal. Wittgenstein's advice was that we "look; don't think," that we scrutinize actual practice rather than theorize about what it must be like by our theoretical lights.

I vacillate between two ways to thinking about Griswold's contribution here. At moments, it seems to me that he has provided an analysis not of forgiveness in general but rather of what it comes to in cases of heinous offenses. My dominant tendency, though, is to suppose that even in such cases, forgiveness is not captured by Griswold's net. ${ }^{3}$ Perhaps Griswold's discussion does illuminate the domain, but in an unexpected way. Griswold's conditions have natural application not so much to forgiveness as to reconciling, reconstructing a relationship that has been damaged or broken by a quite serious, even grievous, moral wrongs.

\footnotetext{
${ }^{3}$ This reflects my reaction in the next sections to Griswold's requirements on the side of the offended party.
} 


\section{Griswold's Analysis: the Side of the Offended Party}

There are three preliminary conditions on the side of the forgiver: the forswearing of revenge, the moderation of resentment, and a commitment to letting go of all resentment. The idea is that unless one has put aside revenge, the process is not well underway. When one has gotten past the vindictive urge, and has begun to moderate one's anger, forgiveness is in process.

The completion of the process, complete forgiveness, has two requirements on the side of the offended party. First, the resentment must be no more. And second, the offended party must reaccept the person. Griswold sometimes describes this as a change in belief: the offended party no longer thinks that the offender is a bad person with whom one should not consort.

There is an important proviso on the first of these conditions: it not sufficient that the resentment is gone, even gone for good. Instead the passing of resentment must occur for moral reasons, because it's the right thing to do. Once the offender has fulfilled the conditions specified above, the victim's resentment, says Griswold, is no longer morally warranted. A consequence is that the offended party is "morally obligated to forswear resentment."

\section{Hesitations: the Two Requirements}

Griswold's "change of belief" requirement This seems to have application only to the most heinous offenses. Except for very serious offenses, such an initial harsh judgment by the offended person - this is a bad person with whom I should not consort-would bespeak an inappropriate judgmental character on the part of the injured party. Nor is it not easy to construe this condition as suggestion something weaker but analogous for more pedestrian offenses. The condition thus raises the issues I raised above about conditions that apply only to extreme cases.

Griswold's forswearing resentment idea This presents a new problem and from a different direction. To suggest that forgiveness is not complete until resentment is eradicated, virtually obliterated, seems too idealized to have purchase in actual cases, even those that involve heinous offense. But if the condition is unrealistic even for the extreme cases, this militates against the equation of extreme with perfect cases, Platonic paradigms.

To begin with the cases of heinous offense, total eradication of resentment is virtually impossible for most people, and perhaps not desirable. Only a saint would be capable of a total elimination of her resentment towards those who, for example, performed a genocide that included her loved ones. And in ordinary cases of personal, forgivable offense, forgiveness involves "getting past" one's resentment. But this usefully imprecise expression hardly suggests that under no conditions might any resentment arise again.

I apologize, you forgive me, and our relationship no longer bears the burden of that offense. I am forgiven. But if I do it again, the former offense may re-emerge in your thinking with renewed resentment. Alternatively, you may have forgiven me, but on the occasion of a book you are reading, or a movie you are watching, 
or another incident with another person, or on many other sorts of occasion, the old offense may come to mind and there may well be the taste of resentment. In some such cases it will be natural to say that the forgiveness had its limitations, that it was not complete. But certainly not in all cases. A certain amount of lingering, hardly noticed, resentment is natural, unremarkable, and compatible with having forgiven.

\section{Hesitation: the Moral Environment of Forgiveness}

I called attention earlier to Griswold's emphasis on moral anger. In fact Griswold's picture of the entire domain is a highly moralized one. A potential forgiveness situation paradigmatically begins with an unjustified moral intrusion. This typically results in a justified moral anger on the part of the offended. But the justification comes to an end when the offender fulfills the conditions specified, 1-6 above. These conditions both involve the moral repair of the offender, and the reaching out to the injured party to repair the moral damage. She asks the offended for forgiveness. And the offended, if he is to do his moral duty, must grant the forgiveness that only he, with his unique moral standing, is in a position to grant. ${ }^{4}$ That is, he must forswear resentment; he must "swear it off" as we might say, since it is no longer morally justified. If, as is often the case, that resentment lingers - if his duty cannot be accomplished at once- then the forgiveness is not complete. When resentment is finally forsworn, we have forgiveness, full, complete, perfect.

As noted, Griswold requires not only that the resentment be permanently eliminated, but that this happen for moral reasons, namely the offended party recognizes that her resentment is no longer warranted. This seems to me to make forgiveness too much a matter of moral calculation and reflection. When you apologize to me in a heartfelt way, I am moved to forgive, resentment recedes, etc. Perhaps I am touched by your reaching out. The wound is healed. In other cases perhaps there was no deep wound; no real resentment to speak of. Your sincere apology is all that I need to put what happened behind us. In many such cases, I forgive, but not because I am motivated to do so by moral thinking or calculation. That would be the proverbial one thought too many. Instead, my resentment lifts; I no longer resent, period.

Contrast this with a case in which the wound is unhealed. Perhaps you have done your part to apologize in a heartfelt manner but the offense is one to which I'm particularly sensitive. At a certain point, I make a conscious, deliberate effort to overcome my resentment. I do so-it takes a special exercise of the will and of conscience-because it is the right thing to do. The latter situation is also part of human experience. But it is hardly the norm. Why make it so?

Indeed there are examples that take us far from Griswold's model of these things. Perhaps you have injured me; perhaps it really stings. But perhaps I know you, and care about you; I know your history, and the some of the difficulties you faced

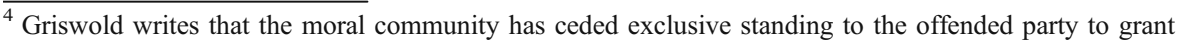
forgiveness.
} 
earlier in your life, perhaps as a child, perhaps in a first marriage. I am ready to forgive without an explicit apology. Perhaps we look in each other's eyes and that's more than enough. Or perhaps I do not even need that much in order to let the resentment go. I am hardly here forswearing resentment because it is no longer warranted. Perhaps resentment is indeed still, technically speaking, warranted; surely another who did not approach the situation as I am doing would be not offending any moral norm if he still felt resentful. There was, after all, no apology. But given how I am approaching the situation, the question of warrant simply drops out as irrelevant. Notice that my willingness to forgive in such cases in no way exhibits any sort of lack of self-respect; nor is it condoning untoward behavior. It's uncontroversial that what you did was offensive. Griswold's analysis seems insensitive to the ethical realities in such cases.

Something I felt to be particularly jarring about what I'm calling Griswold's moralizing of the situation is Griswold's (and others) bringing to bear legal terminology on the ethical life. The question is whether concepts like justification, warrant, obligation and moral duty are the pivotal ones in potential forgiveness situations. A really striking example was Griswold's idea that the moral community cedes to the offended party the moral standing to be the sole purveyor of forgiveness. ${ }^{5}$ That, and the role of justification and warrant throughout Griswold's discussion.

Bernard Williams and others have objected to what they call scientism, the (mis) application to various domains of philosophy of modes of thought and explanation that derive from the sciences. Parallel to such scientism is legalism, the imposition of legal categories on the ethical domain. The matter is of course quite controversial. ${ }^{6}$

\section{Secular and Religious Approaches to Forgiveness}

When the APA approached me to comment on Griswold's book, Charles expressed interest in my articulating a religious perspective that might contrast with his secular perspective. The topic of secular and religious perspectives on forgiveness, and on ethical matters more generally, is of great interest to me. While I am skeptical of religion's ability to provide a logical or philosophical foundation for ethics, I do think that a religious outlook provides important perspective on the ethical life, forgiveness an important case in point. The topic deserves much more discussion, but here is a sketch from my own religious orientation.

\footnotetext{
${ }^{5}$ P. 52. On page 48, Griswold writes that "the victim alone owns the moral right to forgiveness." On pp. 118-119, Griswold discusses standing in connection with "third-party forgiveness." For politically inspired vocabulary in addition to the legel, see Pamela Hieronymi, "Articulating an Uncompromising Forgiveness," Philosophy and Phenomenological Research, Vol. LXII, No. 3, May 2001, who sees the resentment and anger as expressive of moral protest.

${ }^{6}$ See my paper, "The Significance of Religious Experience," (forthcoming, The New Scholasticism; also available on my website: http://www.philosophy.ucr.edu/people/faculty/wettstein/index.html)

I note there the same legalizing tendency in epistemology, specifically in philosophical theorizing about the justification of religious belief. The key notions are again warrant, justification, and obligation. In both domains, ethics and epistemology, the matter is controversial and to many the legalistic turn will seem perfectly natural. In the epistemic realm, my own view is that we would do better to worry about whether we are being epistemically responsible than whether we are justified, the latter connected with granting too much respect to the skeptic, or so I argue in that paper.
} 
It is characteristic of the Jewish religious sensibility (first emphasized in the prophetic literature) to see God and the people as bound in a quasi-marital relationship. Our love for God, and God's love for us, are thus modeled on human love relationships, more than they are in say in various strains of Christianity (and to some extent also in various strains of Jewish and other traditions), where a person's love for God is something like the worship or adoration of perfection, and God's love for persons is a matter of undeserved grace.

Given the intimacy, intensity, and domesticity of the relationship between God and the people, it is not surprising that frictions are engendered. We often fail to live up to our responsibilities to God, sometimes in how we treat Him per se, often in our relationships with one another. ${ }^{7}$ On his side, God is angry and vengeful, silent, absent.

It is characteristic of the Hebrew Bible and Jewish religious sensibility to be blunt about the mutual failures. God tells the prophet Hosea to marry a prostitute; perhaps to convey to him a sense of what it feels like to God to be intimately associated with Israel. At the same time that book powerfully expresses God's commitment to the people; even his longing for them. On the other side, there is a folk story about a group of inmates at Auschwitz who put God on trial for crimes against humanity, find Him guilty, and then proceed to their afternoon prayers. ${ }^{8}$ And just as God longs for His people, we think of him as flawless, for example, (sometimes) in Psalms. Real love relationships are like that. At one moment one is intoxicated with one's lover and her virtues; at other times, one can feel estranged, alienated and the like. ${ }^{9}$

Forgiving one another and the virtue of forgivingness, it should go without saying, must play an enormous role in such relationships. I'll focus here on God's forgivingness, for the Bible one of God's cardinal virtues. God is said to be longsuffering (absorbs many stings), quick to (stands ready to) forgive, does not let his anger consume (it consumes neither Him nor us). ${ }^{10}$ We are told to be like Him in these ways, and further (like Him) not always to hold one's tongue but in the right context to rebuke one another for wrongdoing. This among the commandments is one of the most difficult to get right since it amounts to pointing out the foibles and wrongdoings of another with love and sensitivity, and without condescension. None of this implies that anger is never appropriate; for one sufficiently ethically developed, some sorts and degrees of anger are compatible with love, sensitivity, and a lack of condescension. ${ }^{11}$

\footnotetext{
${ }^{7}$ When one fails to treat another appropriately, an evil in itself, one at the same time violates trust with God.

${ }^{8}$ Even if it's only a folk story, it's existence tells us something about the cultural/religious outlook of the folk. See Elie Wiesel, The Trial of God, Schocken Books, 1995.

${ }^{9}$ In the 1948 Academy Award winning film, The Best Years of Our Lives, a wife of many years says to her daughter about her husband and their to-all-appearances very successful and happy marriage, "If you only knew how many times we had to fall in love again." Such is the fate of God and Israel.

${ }^{10}$ These remarks prompt questions about how God's fierce anger in the Bible comports with his being long-suffering and with his anger not consuming. Also pressing is the problem of injustice in the world, the problem of evil. For my approach to the latter see my paper, "Against Theodicy," in Proceedings of The Twentieth World Congress of Philosophy, available on my website.

${ }^{11}$ So I sum up my sense of the matter. But there is a truly extensive rabbinic literature on anger, much of it concerned with the perils of anger. Unlike the philosophic literature I've been discussing that sees moral anger as appropriate, justified, as the correct reaction to injury for a person morally and personally wellsituated, the emphasis of the rabbinic literature is on the ideal exemplified by God's forgivingness. Perhaps there is the suggestion here that what forgiveness overcomes is not always anger; offense creates rupture and forgiveness reestablishes harmony.
} 
My interest in a religious perspective and specifically the biblical perspective just sketched is not because I think that religion makes possible some special and perhaps superior kind of forgiveness, one that is unavailable to a purely secular outlook. Rather it sheds light on what we humans are up to in forgiving one another. One point of special interest is the Bible's domesticating of forgiveness, the quasimarital relationship mentioned. Focusing our thinking about forgiveness on situations of intimacy seems salutary for as noted proximity engenders friction and forgivingness becomes an important virtue. I turn now to a rough and ready account of the virtue, one that is inspired in part by the discussion of the biblical perspective.

\section{The Virtue of Forgivingness}

As a preamble, I want to mention a remark of my colleague Larry Wright, a remark that I alluded to above. Wright suggested that we human beings would do well to forego some of our anger in favor of an increased sense of irony, a kind of cosmic irony. I took this to be a remark in the spirit of Spinoza; one with a refined sense of human limitation and some ability to see things "under the aspect of eternity" may be less surprised and less angry at the human foibles that come in one's direction. This is no matter or making excuses or condoning injurious behavior. One remains committed to being a certain sort of person, to teaching this to one's children, etc. One who has internalized something of this perspective seems to me on the road to becoming a more forgiving person.

My sketch:

- A forgiving person is likely to absorb more stings than an unforgiving person, and not because of a lack of self-respect or anything of the sort.

- She is also more apt to forget such stings as have occurred, at least the minor ones, and even not so minor ones, again not at the cost of self-respect, etc. Forgetting, in the right context, to the right extent, comes to seem like an important aspect of the virtue.

- Crucially, she also knows the limits, at what point it's important not to hold one's tongue, to protest wrong, and the like. This is of course related to self-respect.

- In contexts where apology is owed her, she is unlikely to require a full narrative of the sort discussed by Griswold (major moral breaches aside of course).

- Her interest in not humiliating the other similarly makes it entirely natural that she not be much interested in any repudiation of the self that did the damage (again major breaches aside).

- In contexts where apology is owed her and done in the right spirit and to the roughly right degree of detail, she finds herself spontaneously less angry. She does not forego her anger (since it's no longer warranted), as one foregoes things one might still desire.

- She is not apt to reduce the other to less that he is, to one who is "just an offender" even while the offense still hangs in the air.

My characterization of the virtue of forgivingness makes strong contact with a number of my earlier hesitations about Griswold's analysis of the act or process of 
forgiveness. At the level of detail, many of Griswold's central foci just do not figure in the virtue I've been describing, for example, Griswold's emphasis on the dutymotivated foregoing of resentment. ${ }^{12}$ But perhaps more important - this at the level of the picture of the domain - the moral reckoning so central to Griswold's account violates the spirit of what I'm suggesting. We need to shift attention, or so my sketch suggests, from questions of justification and the agent's sense of his duties to affective matters like love, generosity of spirit, and the desire to bridge the gulf that hurt creates. $^{13}$

To thus comment on the need to shift direction is not yet to articulate an alternative picture of forgiveness, something I cannot yet do to my satisfaction. What exactly is it to forgive? Is forgiveness a single thing - an act or process - subject to some sort of analysis? Are terms like "act" and "process" adequate? Of course, there are examples where forgiveness seems to consist in an act; I ask for forgiveness; you respond that I am forgiven, and the issue never arises again for either of us. Sometimes "process" seems just right; one works for some time on forgiving a dead parent and at some point the process seems to have taken hold. But there are examples that seem to involve nothing of these sorts; my friend asks for forgiveness for something that took place a while back, and I respond that I forgave him for that a long time ago, this despite the fact that I never explicitly, in some mental act or verbal remark, did so. What transpired was the gradual passing of bad feeling. In many such cases forgiveness seems bestowed en passant.

Perhaps what we have is a non-uniform array of cases-examples of forgiveness - that resemble each other in complicated ways. Sometimes, the offended party's anger is understandable and something to be overcome. Sometimes, anger is hardly present or not present at all; nevertheless, the offense created a rupture. Sometimes the forgiveness is a more or less datable act or event. Sometimes it's more like a lingering process, one that is only more or less complete. Sometimes the offender is forgiven but not by way of some intentional act. Sometimes forgiveness requires elaborate apology, sometimes with a detailed accounting of how such a thing could happen; sometimes not at all... Perhaps we have here what James and Dewey suppose about religion, and what for Wittgenstein became a central analytical tool, the idea of a rough assemblage that for good reason have come to be thought of, and so in an important sense have come to be, a single phenomenon.

Let me conclude by saying again how much I appreciated and learned from Griswold's book. Philosophical differences aside, I particularly appreciated many of

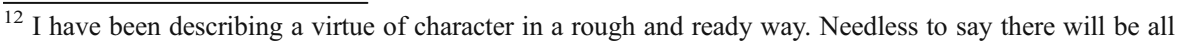
sorts of variations in actual cases. A person who is virtuous in the respect in question may, if very sensitive on a certain topic, have to forego her desire to hurt back. She may have to work at letting go of her anger because it's no longer fair, etc. These are of course some of the features that are emphasized by Griswold. But where he makes them internal to the nature of forgiveness, I see them as reflecting special circumstances, human foibles, and the like.

${ }^{13}$ I am grateful here to (my recollection of) a comment of Tom Olshewsky at the APA symposium which expanded my focus to include generosity of spirit. His point was that forgiveness might be related (perhaps even etymologically) to givingness. Jeff Helmreich, in a related comment, emphasized what I think is a Levinasian perspective according to which forgiveness paradigmatically derives from a departure from the stance of the moral judge and the taking up of a very different stance, one that reflects empathy and love.
} 
its insights and emphases, for example, Griswold's distinguishing between, and his sustained attention to, the relevant virtue of character and something else that is difficult to be clear about, something that we bestow on one another. Moreover, the granting of forgiveness, as Griswold explains, is no simple bestowal; it involves ethical commitments that are extended over time. ${ }^{14}$

Open Access This article is distributed under the terms of the Creative Commons Attribution Noncommercial License which permits any noncommercial use, distribution, and reproduction in any medium, provided the original author(s) and source are credited.

\footnotetext{
${ }^{14}$ This paper derives from my Pacific APA comments in Pasadena, March 2008 in a symposium on Griswold's Forgiveness. I am grateful to Charles Griswold for discussions of these matters, and to Michael Goerger and especially to Jeff Helmreich for helpful discussions both of the Griswold book and of what went into this paper.
} 